vessel's position if she has seen us and does intend to change course. Things can be more difficult at night, when it is harder to estimate distance off. Lights may have just appeared through murk, may be within five minutes of us and it will take that long to set up and execute a gybe safely, but the merchant ship may have seen us on radar for over a quarter of an hour. The old recommended strategy was to shine the torch or ignite a white flare.

Another strategy is to use vHF, although there are mixed opinions about the merits of this. I know that there is a dislike in some areas about the use of vHF for collision avoidance. However I have heard commercial ships calling on Ch. I6 and agreeing avoidance tactics. Indeed, there are some ports where it is recommended that all ships monitor the port control channel, and also some where it is mandatory to report, even if only passing through the entrance channels. I, like many other yachtsmen, keep the vHF set on with a cockpit loudspeaker (to avoid disturbing the sleep of the watch below) and sometimes a handset near the steering position for use in such circumstances. There have been times when I have called on Ch. I 6 , identified our position, relative bearings and course in the hope of agreeing a strategy with the commercial vessel. When a reply is obtained, the exchange is always courteous and helpful, one or both of us changes course and we rarely have to make the more difficult manoeuvre. However, it is common experience among yachtsmen that very few of these calls will be answered. Would any of your contributors like to help us by explaining this and suggesting the most appropriate strategies for the benefit of both groups?

If I may presume so far, might I suggest that a common factor in this subject, and that of conflicts in inshore waters, is that yachtsmen often do not know the constraints affecting commercial shipping or their intended changes of course. Communication to provide information would help. Much has been done to help yachtsmen to foresee the changes in inshore waters but some manoeuvres in the open sea can remain puzzling. Although not a rough weather situation, I remember being overtaken in perfect visibility by a coaster of about 500 g.t on an almost identical course and doing about 8 knots to our 6 . We must have been visible for over an hour. We were obliged to turn away to avoid being run down, but the vessel then turned right across our bows to a position which could have been reached by passing us on the other side. I presume that there was a reason. A short vHF call, however improper, would have enabled the master to forewarn us of his intentions and it would have been easy for us to move to a parallel course a few hundred yards to one side while he was still several miles astern.

KEY WORDS

I. Collision avoidance. 2. Small boat navigation. 3. Communications.

\title{
Stability, Trim and Stress as Navigational Considerations
}

\section{Captain T. Fales}

I INTRODUCTION. A vessel's stability affects her seaworthiness, certain stresses to which her hull and machinery are subjected and thus her speed of advance and the comfort and safety of those aboard. Her draught requires certain minimum depths of water, limits her speed in certain wind and sea conditions, affects the way she handles in all circumstances and her fuel consumption. Trim affects her seaworthiness, handling, fuel consumption and required depth of water. The bending moments and shear stresses 
to which her hull is subjected in a given condition of loading affect the duration of her useful life.

If we accept 'the process of directing the movements of a craft expeditiously and safely from one point to another', as the definition of navigation', then a vessel's stability, trim and stress are navigational considerations.

2. SтAвіLity. Minimum legal standards for $G M$, or metacentric height, are determined by the authority under which a vessel operates. The authority's regulations conform to IMO standards and have the force of law. If a vessel has neutral or negative $G M$, commonsense, regard for human life, insurance regulations, and international law forbid her sailing; cargo and/or ballast must be rearranged before the voyage is undertaken. The navigational problem does not arise since the vessel cannot leave her berth.

In nearly all imaginable circumstances at present, thanks to errors and negligence of others in the past, the minimum $G M$ required by the authority is sufficient to ensure the vessel's positive stability in any sea and weather conditions which her construction and arrangements will permit. However, if during the voyage a reduction of $G M$ occurs, the vessel may have to seek more clement meteorological conditions and calmer seas. Her speed and fuel consumption will be negatively affected. It is therefore incumbent on her Master not only to know his $G M$ before departure but also to know what it will be during the entire voyage when free surface appears and the weight of fuel in the double bottoms decreases.

Excessive stability is another matter. Under some circumstances it can cause the loss of a vessel. The author is aware of a ship which foundered some years ago due to excessive GM. Loaded with heavy machinery whose lashings parted and whose shoring gave way during rapid and precipitous rolling, a bulldozer careered through the framing and shell plating on the starboard side of number 4 tween deck and she went down with a loss of eight lives.

In that particular instance it seems reasonable to believe the tragedy could have been averted by lowering her metacentric height before the voyage was undertaken or, at the very least, when heavy weather was encountered.

A simple formula is commonly used to estimate the rolling period when $G M$ is known:

where,

$$
T=0.44 B / \sqrt{G M}
$$

$$
\begin{aligned}
T & =\text { rolling period in seconds } \\
B & =\text { vessel's beam in feet } \\
G M & =\text { vessel's metacentric height }
\end{aligned}
$$

The prudent navigator will include this calculation in his stability analysis of the voyage he is about to undertake.

Since $0.44 B$ is a constant for any given vessel the navigator need only divide it by the square root of $G M$ in feet to find the rolling period in seconds for any particular metacentric height. Thus a vessel of 90 foot beam will have a rolling period of:

$39^{.6} \mathrm{~s}$ if her $G M$ is 1 foot

28.0 if her $G M$ is 2 feet

17.7 if her $G M$ is 5 feet

12.5 if her $G M$ is 10 feet

10.2 if her $G M$ is 15 feet

8.9 if her $G M$ is 20 feet

If such a vessel is rolling 20 degrees to each side, the stresses provoked by a rolling period of 10 seconds will be large. Since : Force = Mass * Acceleration, a stiff ship in heavy seas not only has a short period of roll but also a large amplitude of roll. 
This condition will also create unsafe and uncomfortable conditions for all on board. The comfort of those aboard is an economic consideration, even if an indirect one, for personnel deprived of proper rest cannot be expected to function at their best. Higher accident rates are the inevitable statistical result, higher $\mathrm{P}$ and I premiums the inevitable financial consequence.

There is a simple, quick, and easy way to reduce excessive metacentric height: by creating free surface. Is there a deck officer at sea today who has not been subjected to mournful homilies and dire caveats concerning the dangers of free surface? This is as it should be, for unintended, unplanned or unsuspected free surface is a dangerous, and quite possibly fatal condition in any vessel. The serious student of stability, however, understands that free surface can enhance as well as degrade the security and performance of his vessel.

Consider a vessel in a seaway; unless the sea and swells are from directly ahead or dead astern, she must roll if she is not to become a breakwater and be subjected to intolerable stresses. Once in motion angular acceleration is the primary cause of racking stresses on her hull and machinery. As we have seen above, the factors of angular acceleration are angle and speed of roll. A stiff vessel in a heavy seaway will roll to large angles and she will roll quickly.

Every navigator knows that synchronous rolling, to be suspected if the period is between 9 and I I $\mathrm{s}$, is extremely dangerous. The navigator disposes of three and only three options to break synchronous rolling: alter course, alter speed, alter metacentric height. Once synchronous rolling has begun only the first two choices are available. Alterations of course and or speed can only augment passage time and so diminish the vessel's economic performance. The prudent navigator's solution to this problem is to determine his rolling period before leaving port and to modify it before encountering heavy weather if it is not satisfactory.

Virtual rise of the centre of gravity caused by free surface is given by the formula:

$$
G G^{\prime}=b^{3} l r / 420 \text { Displacement }
$$

where

$$
G G^{\prime}=\text { Rise of centre of gravity in feet }
$$

$b=$ breadth of compartment

$l=$ length of compartment

$r=$ density of liquid in compartment

divided by density of liquid

supporting the vessel

Since $b, l$, and in most cases $\mathrm{r}$, and 420 are all constants it is a simple matter to compute a free surface constant for each liquid compartment in the ship. Therefore, to compute the virtual rise of the centre of gravity due to any compartment being slack one need only divide its constant by the vessel's displacement at that time.

Transposing the formula:

$$
T=0.44 B / \sqrt{G M}
$$

to solve for $G M$ we have :

$$
G M=\left(0.44^{B / T}\right)^{2}
$$

The navigator can now determine what metacentric height will give his vessel the rolling period he desires. Before reducing his $G M$ the prudent navigator will recall that the righting arm, $G Z$, not $G M$, is the determinant of dynamic stability and will consult his stability curves to ensure that the new $G M$ will provide sufficient dynamic stability. He will also bear in mind that too slow a rolling period will result in seas breaking over his vessel, with the attendant dangers to personnel, possibilities of structural damage and eventual problems with deck cargo, if carried. 
To illustrate : let us suppose a loaded vessel with a beam of 90 feet, displacing 40000 tonnes, has five double bottoms divided into three sections longitudinally and that numbers 3,4 , and 5 are each 100 feet long, centre tanks 50 feet in breadth and wings 20 feet in breadth. All are dry, the metacentric height is 8.5 feet, and the rolling period $13.6 \mathrm{~s}$.

The navigator would prefer a longer rolling period to diminish the risk of synchronous rolling, to diminish the dynamic forces on the lashings of his deck cargo and for the greater comfort of his crew.

The free surface constant for each centre tank is $29762,\left(50^{3} \times 100 / 420\right)$. Dividing this predetermined free surface constant by the vessel's displacement yields 0.74 feet. Each tank has a capacity of 714.3 tonnes when filled with sea water, $(50 \times 100 \times 5) / 35$, 10 percent of the volume of each tank, or $71^{\circ} 4$ tonnes will provide the necessary free surface effect. The navigator will choose the two tanks nearest midships, (unless he wants to alter his trim), and so reduce his $G M$ from 8.5 feet to $7 \cdot 0$ feet and increase his rolling period from $13.6 \mathrm{~s}$ to $15 \mathrm{~s}$. This will add 143 tonnes or 0.4 percent to his displacement.

To achieve maximum seaworthiness for the current voyage, other calculations may be necessary. Such calculations may include angular acceleration, minimum $G M$ required to limit maximum angle of heel if a particular parcel of cargo shifts, and the change in trim which will result from any such operation.

Added water ballast will create free surface effect; slacking pressed-up tanks will achieve the same purpose.

3. TRIM. Trim may have surprising, almost mysterious, effects on speed and fuel consumption. The author recalls a product carrier in which he served, a I 5 -knot vessel ; the average speed during the ballast leg was increased half a knot by ballasting number 3 wings, rather than number 4 wings. Concomitantly, hull stress was considerably reduced.

Trim, as a navigational consideration, differs from stress in that it affects a vessel's speed and fuel consumption in all weather conditions. In general its influence will be more apparent in good weather than in high winds and heavy seas. Cargo distribution is the major determinant of trim in a laden vessel, but a small amount of ballast added or shifted from forepeak to afterpeak, or vice versa can alter fore and aft draughts enough to measurably affect speed and handling qualities.

Every navigator is aware that, in general, a vessel trimmed by the head will steer erratically, even in good weather, and handle awkwardly when manoeuvering. But what of the extra fuel consumption and slower speed on an ocean passage due to continuous rudder movement, (resistance varies as the sine of the rudder angle), and the other manifestations of 'crankiness': higher cylinder temperatures in diesel engines, unnecessary additional wear on the auto-pilot and the steering engine...? The fact that his vessel must leave or arrive at a port on an even keel is no reason for her navigator to leave the afterpeak empty between departure and arrival, if filling it completely or partially will improve vessel performance and reduce vibration.

Many subtleties of trim are, and seem fated to remain, mysterious in their effects on vessel performance until navigators turn their attention to the problem. There are presently two reasons for this :

a. naval architects rarely if ever provide information regarding ideal or desirable trim in any condition of loading.

b. operating personnel do not generally record the apparent influence on speed and fuel consumption, if they have observed it. Even the most detailed voyage abstracts do not reflect deadweight, metacentric height, trim or hull stress. 
4. STRESS. Longitudinal stress, as determined by the calculation of shear force and bending moment, is a prime consideration of good seamanship. The navigator of any vessel whose shear force or bending moment approaches 90 percent of that permissible, would be well advised to avoid areas where he might encounter heavy weather. If this precaution requires a deviation from the most desirable route between departure and arrival, the vessel's economic performance, her efficiency, will be proportionately reduced. The solution is careful consideration and meticulous calculation of all alternatives before the voyage begins.

5. MEASURING THE BENEFITS. How can the navigator measure the benefits of a more appropriate metacentric height during an ocean passage? How does he know if cargo would have shifted or come adrift from its lashings? How does he know if lack of sleep due to more violent rolling would have caused his bosun to fall on deck and injure himself, or his steward to spill hot cooking oil on his leg?

The answer is, of course, that he does not know. He does know, however, that no one has been injured, that no cargo has shifted or gone adrift, that he has not uselessly exhausted his crew or himself because of violent rolling. He knows that he has not been forced to reduce speed or change course and go hundreds of miles out of his way to avoid violent rolling. He knows that his efforts have reduced his owner's $P$ and I premiums/calls. He knows that he has 'directed the movements of his craft expeditiously from one point to another'.

How can the navigator determine the ideal trim for his vessel at any given displacement/mean draught? He cannot, but he does know that the factors determining his speed are: total wetted surface, residual resistance, and propeller immersion. He also knows that his vessel is finer at the run than she is forward. It is therefore apparent to him that his vessel should be trimmed by the stern, since that condition will reduce wetted surface, immerse the screw more deeply and probably lessen residual resistance. It is also apparent to him that, in general, the less the displacement/mean draught the greater the trim should be as a percentage of length on the load water line. Given the present abilities of computer calculating as applied to naval architecture, is a table of wetted surface values at various draughts an unreasonable request for the navigator to make of the designer?

Residual resistance is the elusive factor in the equation, which is why, as everyone knows, William Froude resorted to the towing tank and why towing tanks are still in use. Given the discrepancies in scale, analysis of residual resistance due to a few inches variation in trim is a lot to ask of the towing tank. The presence of a GPS on the bridge of most vessels at sea today renders the world's ocean full-scale testing tanks. The officer of the watch notes in the chief mate's log: wind and sea conditions, average R.P.M., and other data. Why should he not also record geographic position and speed made good? Storing this data in a memory bank is simple. Submitting the data to statistical analysis is equally simple; the cost negligible. The results remain to be seen. They will surely be interesting.

The navigator free of the drudgery which formerly occupied so much of his time, can turn the focus of his attention from finding out where he is to improving the present and future speed and fuel efficiency of his vessel. He can now know his position at any and every instant with an accuracy inconceivable a few years ago. Computing power, once available only to the wealthiest universities, now lies at his finger tips. He can solve any navigational problem, compute his vessel's stability, trim and stress in seconds, produce a plethora of alternatives in minutes.

What does this freedom from laborious and error-prone calculations change for the navigator? Only the focus of his attention when he is not in crowded waters. His responsibility, his objectives, remain the same as they were in the days of the 
Phoenicians : safer, quicker passages and, since the advent of power-driven craft, greater fuel economy. He now has at his command the means to explore complexities and subtleties which have escaped him for years. The ancient art is ever more fascinating.

\section{REFEREN CE}

1 Bowditch, N. The American Practical Navigator, Volume I. Defense Mapping Agency Hydrographic Center, 1977.

\section{'Whither Astro?'}

\section{Mike Pepperday writes}

In the May issue of the Journal, Mr Parker suggests ${ }^{1}$ that my criticism of the Nautical Almanac Office's calculator instructions ${ }^{2}$ was an unnecessary exercise if it is true that astronomical navigation has been superseded. However, it should surely be the publishing of those calculator instructions which is unnecessary if the sextant is obsolete - rather than my criticism of the said instructions. Well, perhaps Mr Parker is right. It is precisely this obsolescence which inhibits me from submitting a critique of those 'NAO sight reduction tables' which also appear in the Nautical Almanac year in, year out, and which are also irrelevant.

Do we agree - better $S$ than nothing? As I understand it, the least squares solution is also valid where errors are not Gaussian.

The reason I don't discuss confidence zones is partly because there isn't a practising navigator on the planet who knows what they are and partly because they have no point: what is the use of a 95 percent ellipse? No navigator will tolerate being wrong 5 percent of the time. You're wrong or you're right and to the devil with the asymptote. Has any captain yet stood up before a court of enquiry and expatiated on the Gaussian curve? Was he acquitted?

Put it this way. Let there be taken, on a pleasant evening, four or five shots to each of four stars, evenly distributed around the horizon. This was my pre-GPS practice. Suppose the intercepts of the multiple shots agree (though if three agree for a star I wouldn't bother computing another - I only took the fourth and fifth in case one or two intercepts look dodgy), and suppose the $S$ is small (though, because the sights are evenly distributed, the $\mathbf{S}$ is not so important).

Now in this situation I am 'confident' that the fix is within a mile. There are too many double checks for it to be wrong. The only remotely plausible situation where this fix can be wrong in latitude, or wrong in longitude outside of an incorrect clock, would be some remarkably biased refraction condition. In short, to an accuracy of a mile it just can't be wrong. But - BUT - if there is a reef within five miles of the fix my stomach will lurch and I will act on the assumption I am just about to hit that reef.

The above has nothing to do with ellipses. Nothing. Moreover, neither an erroneous clock nor this (quite unbelievable) refraction would be picked up by any $\mathbf{t}, \mathbf{F}$ or chisquared examinations. So forget 'em. I would like to stamp the lesson from this in bold type: The quality of an astrofix is determined by observing procedure, not statistical analysis.

I am sorry if I underplayed the importance of plotting lines in my original article. ${ }^{2}$ I teach it enough. I recommend it for learners. In practice if you take plenty of sights, 